\title{
Editorial
}

\section{Introducing Our New Offspring Journal ... TH Open}

\author{
Gregory Y. H. Lip ${ }^{1,2}$ Christian Weber ${ }^{3,4}$ \\ ${ }^{1}$ Institute of Cardiovascular Science, University of Birmingham, \\ Birmingham, United Kingdom \\ ${ }^{2}$ Aalborg Thrombosis Research Unit, Department of Clinical \\ Medicine, Aalborg University, Aalborg, Denmark \\ 3 Institute for Cardiovascular Prevention, Ludwig-Maximilians- \\ Universität (LMU) and DZHK (German Centre for Cardiovascular \\ Research), partner site Munich Heart Alliance, Munich, Germany \\ ${ }^{4}$ Department of Biochemistry, Cardiovascular Research Institute \\ (CARIM), Maastricht University, Maastricht, The Netherlands
}

TH Open 2017;1:e1-e2.

Welcome to an exciting new development in the growth of Thrombosis and Haemostasis. With an increasing number of manuscripts being submitted to the journal, we are delighted and honored to launch "TH Open" as a brand new, Open Access companion title as from this July 2017, to coincide with the 60th anniversary of Thrombosis and Haemostasis. ${ }^{1}$ The official ceremony to introduce and unveil the newborn journal to the world will take place at the ISTH 2017 meeting in Berlin, Germany.

In a unique collaboration, TH Open will be published by Thieme in cooperation with Schattauer, Publisher of Thrombosis and Haemostasis. Mirroring TH, our new journal will publish original basic research and clinical studies, review articles, letters to the editor, and case reports in vascular biology and medicine covering a wide spectrum of topics.

There will be two routes to submission to the journal. The first will offer authors of high-quality, scientifically sound papers, which could not be published in TH due to pagination constraints, an opportunity to transfer their manuscript, together with the reviewer comments, to TH Open for consideration. The second route is via traditional direct submissions, which shall be subject to full peer review in the normal way.

The emphasis will be on scientifically sound research, regardless of novelty or impact. Thus, we would be very keen to see primary research that may well be valuable confirmation, as well as negative results. We look forward to receiving your papers at https://mc.manuscriptcentral.com/thopen.

Please be sure to check out the TH Open homepage at www.thieme.com/THO where you can already read this first published issue and more.

In our inaugural issue, we have diverse papers from basic science to clinical studies. The inaugural papers from $\mathrm{TH}$ Open deserve a mention. We publish a comparison of the protective effects of $\alpha$ - and $\beta$-antithrombin against vascular

Address for correspondence Prof. Gregory Y. H. Lip, University of Birmingham, Institute of Cardiovascular Sciences, City Hospital, Birmingham B18 7QH, United Kingdom (e-mail: g.y.h.lip@bham.ac.uk). endothelial cell damage induced by histone in vitro. ${ }^{2}$ Also, how ADAMTS13 deficiency worsens colitis and exogenous ADAMTS13 administration decreases colitis severity in mice, ${ }^{3}$ and a study of platelets protecting cardiomyocytes from ischemic damage. ${ }^{4}$

Clinical research also features prominently. We present a subgroup analysis of patients with cancer in XALIA, a noninterventional study of rivaroxaban versus standard anticoagulation for VTE. ${ }^{5}$ We also publish a paper investigating associations between maternal and fetal inherited thrombophilias, placental characteristics associated with vascular malperfusion, and fetal growth. ${ }^{6}$ The IMPROVEDD VTE risk score shows how incorporation of D-Dimer into the IMPROVE score would improve venous thromboembolism risk stratification. ${ }^{7}$ Impact of venous thromboembolism on the formation and progression of carotid atherosclerosis is also demonstrated from the Tromsø Study. ${ }^{8}$

Particularly exciting about the new journal is that it will employ Thieme's unique "Pay What You Want" model for Article Publication Charges, meaning authors can pay any amount they feel appropriate upon acceptance of your article to cover the Open Access charges. This ensures that authors with limited resources are still able to get their research published and disseminated.

As the proud editor-godparents of TH Open, we hope that you share our excitement with this new endeavor. Our new arrival to coincide with the excitement over the 60th anniversary of Thrombosis and Haemostasis demonstrates our commitment to you, with additional opportunities to disseminate your research work.

If you have any questions, feedback, or suggestions, please do not hesitate to get in touch with us and we will be only too happy to enter this into our discussions and future considerations for further evolution.

(c) 2017 Georg Thieme Verlag KG Stuttgart . New York
License terms

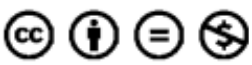

DOI https://doi.org/

ISSN 2512-9465. 


\section{References}

1 Lip GYH, Weber C. Thrombosis and Haemostasis: Past, present and future. Thromb Haemost 2017;117(07):1217-1218

2 Iba T, Sasaki T, Ohshima K, Sato K, Nagaoka I, Thachil J. The comparison of the protective effects of $\alpha$ - and $\beta$-antithrombin against vascular endothelial cell damage induced by histone in vitro. TH Open 2017;1(01):e3-e10

3 Zitomersky NL, Demers M, Martinod K, et al. ADAMTS13 deficiency worsens colitis and exogenous ADAMTS13 administration decreases colitis severity in mice. TH Open 2017;1(01):e11-e23

4 Walsh TG, Poole AW. Platelets protect cardiomyocytes from ischaemic damage. TH Open 2017;1(01):e24-e32

5 Ageno W, Mantovani LG, Haas S, et al. Subgroup analysis of patients with cancer in XALIA: a noninterventional study of rivaroxaban versus standard anticoagulation for VTE. TH Open 2017;1(01):e33-e42

6 Freedman AA, Hogue CJ, Dudley DJ, et al. Associations between maternal and fetal inherited thrombophilias, placental characteristics associated with vascular malperfusion, and fetal growth. TH Open 2017;1(01):e43-e55

7 Gibson CM, Spyropoulos AC, Cohen AT, et al. The IMPROVEDD VTE risk score: incorporation of D-Dimer into the IMPROVE score to improve venous thromboembolism risk stratification. TH Open 2017;1(01):e56-e65

8 Lind C, Småbrekke B, Rinde LB, et al. Impact of venous thromboembolism on the formation and progression of carotid atherosclerosis: the Tromsø Study. TH Open 2017;1(01): e66-e72 